\title{
The influence of temperature variation upon vascular dynamics in cattle as measured by Doppler-image ultrasonography.
}

\author{
B.H. KIRCH ${ }^{1}$, G.E. AIKEN ${ }^{1}$ and D.E. SPIERS ${ }^{2}$ \\ ${ }^{1}$ USDA-ARS-Forage Animal Production Research Unit, Lexington, KY, U.S.A. 40546-0091 \\ ${ }^{2}$ University of Missouri, Columbia, MO
}

bkirch@ars.usda.gov

\begin{abstract}
Two studies were performed to determine if Doppler ultrasound can detect vascular changes in cattle exposed to hot and cold conditions. Three calves per study $(320 \pm 38 \mathrm{~kg})$ were acclimated to $17.5^{\circ} \mathrm{C}$, and then exposed to $32^{\circ} \mathrm{C}$ and $8^{\circ} \mathrm{C}$. Animals were maintained under these conditions for $24 \mathrm{~h}$ and then returned to the original thermoneutral level. Three replicated ultrasound measurements of the median caudal artery were performed. Scans were repeated at $-2,5,23,24$ and $28 \mathrm{~h}$. Blood flow rates of $32^{\circ} \mathrm{C}$ cattle ranged from $27.84(-2 \mathrm{~h})$ to $43.42 \mathrm{ml} / \mathrm{min}$ at $23 \mathrm{~h}$ $(\mathrm{P}<0.05)$. Heart rate was unchanged, but respiration increased from 82 to 120 breaths $/ \mathrm{min}$ at $32^{\circ} \mathrm{C}(\mathrm{P}<0.05)$. Cattle exposed to $8^{\circ} \mathrm{C}$ showed lower flow rates after $23 \mathrm{~h}$ of exposure $(\mathrm{P}<0.10)$ $(29.29$ at $-2 \mathrm{~h}$ to $13.79 \mathrm{ml} / \mathrm{min}$ at $23 \mathrm{~h})$. Blood flow rates of these cattle initially increased after the challenge. At $8^{\circ} \mathrm{C}$, the heart rate was unaffected. Respiration rate decreased from 62 at $-2 \mathrm{~h}$ to 36 breaths $/$ min at $23 \mathrm{~h}(\mathrm{P}<0.05)$ when housed under cool conditions. Arterial cross-sectional area increased from 0.058 to $0.076 \mathrm{~cm}^{2}$ at $5 \mathrm{~h}(\mathrm{P}<0.05)$ exposure to $8^{\circ} \mathrm{C}$ then decreased to $0.043 \mathrm{~cm}^{2}$ at $23 \mathrm{~h}$. The ability of the Doppler-image ultrasound to detect vascular changes demonstrates its use as a tool for assessing environmental stress effects on haemodynamics.

Keywords: tall fescue, Doppler-ultrasound, cattle
\end{abstract}

\section{Introduction}

Tall fescue is a major cool-season forage component of the grazing lands in Kentucky and major portion of the southern United States. Tall fescue is found primarily in the transition zone between the more temperate regions of the Midwest and Northeast and the subtropical regions of the Southeast (Thompson et al. 2001). Cattle grazing tall fescue demonstrate manifestations of fescue toxicosis, which is associated with the consumption of an endophytic fungus (Neotyphodium coenophialum) that is found in the vast majority of fescue pastures in the area (Sleper et al. 1996). The level of toxicosis in cattle varies from lost productivity to sloughing of hooves and tails. A major component of fescue toxicosis is the vascular constriction of peripheral blood vessels and the subsequent alterations in blood flow, which are caused by the binding of alkaloids to $\alpha$-adrenergic receptors in peripheral tissues. As a result of vascular constriction, the ability of the animal to dissipate heat and regulate body temperature is restricted, especially during heat stress (Oliver 2005). This inability of peripheral vessels to dilate may lead to hyperthermia , reduced grazing activity and productivity and, in severe cases, the necrosis of peripheral tissues.

The use of Doppler-image ultrasound technology has been a mainstay in vascular assessment in human medicine for years. Use in the animal agriculture to study blood flow has been utilised in horses (Hoffman et al. 2001; Mario et al. 1997; Raisis et al. 2000). Usage in cattle vascular studies has not been as frequent; however, ultrasound imaging does offer a quick, efficient, and non-invasive way of evaluating the effects of fescue toxicosis on the peripheral vessels of cattle with good repeatability (Raisis et al. 2000; King 2006). The objectives of this study were to evaluate vascular changes of cattle placed under environmental stresses of contrasting ambient temperatures. If vascular changes can be detected in normal animals, this could lead to a protocol to study the effects of cattle grazing endophyte-infected tall fescue.

\section{Methods}

Two independent studies were conducted to establish the ability of the Doppler-image ultrasound to detect vascular changes in cattle due to environmental variation. Three Angus cross-bred calves $(320 \pm 38 \mathrm{~kg})$ were utilised per study. The animals were halter broken and trained to stanchions and fed an identical complete feed ration $(12.9 \% \mathrm{CP}$ and $3.7 \%$ fat $)$ for the duration of the study. The calves were acclimated for 24 hours at thermoneutrality in the Brody Environmental Center at the University of Missouri. The calves were then exposed to either a reduction to $8^{\circ} \mathrm{C}$ in air temperature or to an elevation of air temperature to $32^{\circ} \mathrm{C}$. The animals were housed under each condition for $24 \mathrm{~h}$ and then returned to thermoneutral temperature. Using an Aloka ProSound SSD-3500 ${ }^{\mathrm{TM}}$, a minimum of three B and D-mode ultrasound measurements were taken of the median caudal

Table 1. Vascular responses in cattle exposed to $32^{\circ} \mathrm{C}$ for $24 \mathrm{~h}$.

\begin{tabular}{lcccccc}
\hline Time (hours) & -2 & 5 & 23 & 24 & 28 & LSM \\
\hline Heart Rate (beats per minute) & 87 & 83 & 83 & 85 & 83 & 5 \\
Respiration Rate (breaths per min) & 82 & 42 & 121 & 120 & 61 & 7 \\
Flow Rate (ml/min) & 27.84 & 26.32 & 43.42 & 36.76 & 36.91 & 3.88 \\
Peak Systolic Velocity (ml/min) & 27.14 & 22.91 & 33.51 & 24.83 & 22.23 & 4.53 \\
End Diastolic Velocity (ml/min) & 7.53 & 7.82 & 6.00 & 6.98 & 2.74 & 1.76 \\
Caudal Artery Area $\left(\mathrm{cm}^{2}\right)$ & 0.047 & 0.063 & 0.063 & 0.063 & 0.067 & 0.010 \\
Pulsatility Index & 4.21 & 5.29 & 3.48 & 3.45 & 2.90 & 1.25 \\
\hline
\end{tabular}


Table 2. Vascular responses to cattle exposed to $8^{\circ} \mathrm{C}$ for $24 \mathrm{~h}$.

\begin{tabular}{lcccccc}
\hline Time (hours) & -2 & 5 & 23 & 24 & 28 & LSM \\
\hline Heart Rate (beats per minute) & 81 & 81 & 77 & 79 & 76 & 5 \\
Respiration Rate (breaths per min) & 62 & 82 & 36 & 34 & 53 & 5 \\
Flow Rate (ml/min) & 29.29 & 44.11 & 13.79 & 22.21 & 30.70 & 5.62 \\
Peak Systolic Velocity (ml/min) & 31.74 & 29.31 & 28.26 & 24.78 & 24.31 & 3.75 \\
End Diastolic Velocity (ml/min) & 8.17 & 6.42 & 10.54 & 7.48 & 5.91 & 3.48 \\
Caudal Artery Area (cm $\left.{ }^{2}\right)$ & 0.058 & 0.076 & 0.043 & 0.056 & 0.063 & 0.010 \\
Pulsatility Index & 7.71 & 4.21 & 8.51 & 8.69 & 4.22 & 2.84 \\
\hline
\end{tabular}

artery at the $4^{\text {th }}$ coccygeal vertebrae (Cd4) using a UST-5542 (13 MHz) linear array transducer set to a depth of $2 \mathrm{~cm}$. Crosssectional scans were taken to determine mean arterial lumen area, while longitudinal scans were used to estimate additional flow parameters. Ultrasound scans were performed at -2 (2 hours before temperature change), 5, 23, 24 and $28 \mathrm{~h}$ (4 hours after returning to thermoneutrality) in each test. Blood flow and vessel diameters were evaluated by determining a flow rate for three cardiac cycles in three different scans. The measured points within the cycle included peak systolic velocity (PSV) and end diastolic velocity (EDV), determined, as the name denotes, at the end of the diastolic cycle. An additional variable was pulsatility index (PI), which is a determination of the property or strength of the flow. A high PI is indicative of a high resistance to flow. Mean arterial lumen area was determined by calculating the area of the vessel in cross-sectional views, and heart rate was recorded from the ultrasound scans. Respiration was monitored visually by counting breaths per minute. Data were analysed as repeated measures using PROC MIXED of SAS.

\section{Results and Discussion}

\section{Response at $32^{\circ} \mathrm{C}$}

Exposure to heat stress increased respiration rate from 82 (-2 h) to 120 breaths/min ( 23 to $24 \mathrm{~h})(\mathrm{P}<0.05)$, with no change in heart rate ( 82 beats/min) (Table 1$)$. The increase in respiration rate with increase in temperature (Findlay 1957) would be expected as one avenue for dissipation of heat. In this study, we measured the vasomotor activity of a peripheral artery as a second pathway to dissipate heat. The blood flow rates to the caudal artery increased from $27.84(-2 \mathrm{~h})$ to $43.42 \mathrm{ml} / \mathrm{min}$ at 23 $\mathrm{h}$ of exposure $(\mathrm{P}<0.07)$ in the heat stressed cattle. According to Hardy (1961), vessel dilation due to increased flow to peripheral tissues during heat stress is an avenue of heat exchange. Vessel diameter tended to increase $\left(0.047\right.$ to $\left.0.063 \mathrm{~cm}^{2}\right)$ with the onset of the stress, but was not statistically significant $(\mathrm{P}>0.10)$ due to animal variability. Changes were also noted within the cardiac cycle of the heat stressed animals. When the temperatures were changed, flow rates of the cardiac cycle showed no difference in the flow rates at the peak of the systolic (PSV) portion of the cycle (Table 1). At the end of the diastolic cycle (EDV), there was a decline in the velocity from the thermoneutral level after 24 hours $(\mathrm{P}<0.05$; Table 1$)$. If the vessels were dilated under heat stress, the velocity of flow at the end of the diastolic phase would decrease due to less resistance in the vessel and changes occurring at the peak of the systolic phase would be minimal. In this experiment this was demonstrated as the animal returned to thermoneutral temperatures. The strength of the pulse or PI did decrease due to vasodilatation, as would be expected with heat stress, but was not found to be statistically significant (Table 1).

\section{Response at $8^{\circ} \mathrm{C}$}

Exposure to $8^{\circ} \mathrm{C}$ resulted in a similar heart rate, averaging 79 beats/min, across all five time periods (Table 2). Under this condition, respiration rate decreased from $62(-2 \mathrm{~h})$ to 36 breaths/ $\min (23 \mathrm{~h})(\mathrm{P}<0.05)$, with an increase to 53 breaths/min upon return to the original temperature $(28 \mathrm{~h})(\mathrm{P}<0.05)$ in an effort to conserve internal heat. Exposure to the lower temperature reduced flow rate to the caudal artery after $23 \mathrm{~h}(\mathrm{P}<0.05)(29.29$ at $-2 \mathrm{~h}$ to $13.79 \mathrm{ml} / \mathrm{min}$ at $23 \mathrm{~h}$ ). Blood flow rates of the cattle initially increased after the challenge. At $5 \mathrm{~h}$ temperature reduction, flow rate was $44.11 \mathrm{ml} / \mathrm{min}$, increasing by $14.8 \mathrm{~mm} /$ min over the baseline flow $(\mathrm{P}<0.05)$, but then declined to 13.79 $\mathrm{ml} / \mathrm{min}$ at $23 \mathrm{~h}$. The increase in vasodilatation in response to tissue perfusion and has been demonstrated in both humans and cats (Folk 1974) and is normal with prolonged exposure to cold, where a temporary dilation of the peripheral vessels occurs before returning to constricted flow of the vessel. This was also verified by the arterial area, which increased from 0.058 to $0.076 \mathrm{~cm}^{2}$ at $5 \mathrm{~h}(\mathrm{P}<0.05)$ then decreased to $0.043 \mathrm{~cm}^{2}$ at $23 \mathrm{~h}(\mathrm{P}<0.01)$. The blood flow in the caudal artery at $8^{\circ} \mathrm{C}$ showed no changes in PSV. With arterial constriction, we should see an increase in the EDV. In this instance, we noted a trend toward the highest values at 23 $\mathrm{h}$ (Table 2). The PI also tended to increase with the temperature, but was not significant statistically (Table 2).

When cattle consume endophyte-infected tall fescue there is evidence that alterations of blood flow occur. Evaluations of these changes in the field are difficult, but the use of Doppler-image ultrasonography offers the potential to non-invasively look at vascular changes. In this study, using only three cattle subjected to different ambient temperatures, we were able to detect changes in blood flow rates and vascular dimensions. The increase in flow rates of heat stressed cattle is consistent with vasodilatation, while exposure to the lower temperature produced a decrease in flow consistent with vasoconstriction. Alterations within the cardiac cycle were also noted with EDV decreasing in the heat stress cattle consistent with a vessel offering less resistance due to vasodilatation. The ability of the Doppler-image ultrasound to detect vascular changes due to environmental variation, lends itself as a useful tool for assessing environmental stress effects on haemodynamics.

\section{REFERENCES}

Findlay, J.D. 1957. The respiratory activity of calves subjected to thermal stress. Journal of. Physiology 136: 300-309. 
Folk, G.E. Jr. 1974. Responses to a cold environment. pp. 133200. In: Textbook of environmental physiology. Eds. Folk, G.E. Jr. Lea and Febiger. Philadelphia, PA.

Hoffman, K.L.; Wood, A.K.W.; Griffiths, K.A. 2001. Doppler sonographic measurements of arterial blood flow and their repeatability in the equine foot during weight and non-weight bearing. Research in Veterinary Science 70: 199-203.

King, A.M. 2006. Development, advances, and applications of diagnostic ultrasound in animals. Veterinary Journal 171: 408-420.

Mario C.; Pietra M.; Gandini G.; Boari, A.; Guglielmini, C.; Venturoli, M. 1997. Pulsed wave-doppler ultrasonography evaluation of the common carotid artery in the resting horse: Physiologic data. Vet Radiology and Ultrasound 38: 200-206.
Oliver, J.W. 2005. Pathophysiologic response to endophyte toxins. pp. 291-304 In: Neotyphodium in cool-season grasses. Eds. Roberts, C.A.; West C.P.; Spiers, D.E. Blackwell Publishing. Ames, IA.

Raisis, A.L.; Young, L.E.; Meire, H.B.; Taylor, P. M.; Walsh K.; Lekeux, P. 2000. Variability of dopper ultrasound measurements of hindlimb blood flow in conscious horses. Equine Veterinary Journal 32: 125-132.

Sleper, D.A.; West, C.P. 1996. Tall fescue. pp. 471-505. In: Cool-season Grass Forages, Agronomy Monograph No. 34. Eds. Moser, L.E.; Buxton, D.R.; Casler, M.D. ASA, CSSA, and SSSA. Madison, WI.

Thompson, F.N.; Stuedemann, J.A.; Hill, N.S. 2001. Anti-quality factors associated with alkaloids in eastern temperate pasture. Journal of Range Management 54: 474-489. 